\title{
Co-infection of Epstein-Barr virus and human papillomavirus in human tumorigenesis
}

Ying Shi ${ }^{1,2,3}$, Song-Ling Peng ${ }^{1,2,3}$, Li-Fang Yang ${ }^{1,2,3}$, Xue Chen ${ }^{1,2,3}$, Yong-Guang Tao 1,2,3* and Ya Cao ${ }^{1,2,3^{*}}$

\begin{abstract}
Viral infections contribute to approximately $12 \%$ of cancers worldwide, with the vast majority occurring in developing countries and areas. Two DNA viruses, Epstein-Barr virus (EBV) and human papillomavirus (HPV), are associated with $38 \%$ of all virus-associated cancers. The probability of one patient infected with these two distinct types of viruses is increasing. Here, we summarize the co-infection of EBV and HPV in human malignancies and address the possible mechanisms for the co-infection of EBV and HPV during tumorigenesis.
\end{abstract}

Keywords: Epstein-Barr virus, Human papillomavirus, Co-infection, Nasopharyngeal carcinoma, Cervical cancer, Breast cancer, Prostate cancer

\section{Introduction}

Oncogenic viruses include various classes of DNA and RNA viruses that are necessary but not sufficient for the development of all types of malignancies. A unifying theme is that cancer develops in a minority of persistently infected people and only after many years of chronic infection [1]. The majority of these cancers result from infection with an oncovirus. Viral infections contribute to approximately $12 \%$ of cancers worldwide, the vast majority $(>85 \%)$ of which occurs in developing countries and areas [2, 3]. Epstein-Barr virus (EBV) and human papillomavirus (HPV), which are DNA viruses, were reported to be linked with $38 \%$ of all virus-associated cancers [4]. EBV is an oncogenic gamma-1 herpesvirus that infects more than $90 \%$ of the adult population worldwide, and it has powerful transforming potential for B lymphocytes in vitro, contributing to several lymphoid malignancies, including B, T, and natural killer (NK) cell lymphomas and epithelial carcinomas such as nasopharyngeal carcinoma (NPC) [4-9]. The viruses associated with the greatest number of cancer cases are HPVs, which cause

\footnotetext{
*Correspondence: taoyong@csu.edu.cn; ycao98@vip.sina.com

${ }^{1}$ Cancer Research Institute, Central South University, Changsha 410078,

Hunan, P. R. China

Full list of author information is available at the end of the article
}

cervical cancer and several other epithelial malignancies [10].

The probability of a single patient who is infected with two or more distinct types of viruses is increasing [11, 12]. Viral infections within carcinoma cells are not mutually exclusive. In the last 20 years, substantial attention has been paid to the observation that human immunodeficiency virus (HIV)-infected patients have a high risk of developing some cancers such as cervical carcinoma and some non-Hodgkin lymphomas [12]. Notably, cancers arising in the context of HIV-induced immunosuppression are usually associated with subsequent infection by oncogenic viruses such as EBV and HPV [13]. However, the detailed mechanism of the cooperation remains largely unknown, and further studies are needed to address whether this cooperation plays a critical role in tumor development.

The implication that HPV has a role in the carcinogenesis and prognosis of cervical cancer is well established. However, many studies have found that HPV infection is linked to NPC as an etiologic factor [14-17] and that EBV is also present in cervical cancer $[18,19]$ and prostate cancer [20]. The co-existence of both EBV and HPV has also been reported in other epithelial cancers, such as breast cancer [21]. The co-infection of EBV and HPV plays an important role in the initiation of a neoplastic 
transformation of carcinogenesis [22]. Interestingly, there is an interaction between EBV and HPV (whole viruses) in vivo as well as an interaction between HPV and EBV oncoproteins [e.g., latent membrane protein 1 (LMP1) reduces apoptosis in vitro] [23]. Whether the host is co-infected with two viruses, such as EBV and HPV, is unknown. Here, we discuss the co-infection of EBV and HPV in human malignancies and possible common characterizations in the molecular mechanisms of tumorigenesis.

\section{Co-infection of EBV and HPV in NPC}

NPC is a common tumor in South China and Southeast Asia, but it is a rare disease among Caucasians [24, 25]. For many decades, the major etiologic factors proposed for NPC pathogenesis have included genetic susceptibility, environmental factors, and EBV infection [26]. However, although EBV infection is regarded as the primary factor for NPC, NPC patients are occasionally EBV-negative $[27,28]$. Over the last decade, several studies have reported that HPV also exists in some EBV-negative NPC patients [14-17, 29]. HPV is considered one of the cofactors because it can transform epithelial cells, and the HPV DNA level is high in NPC biopsies.

The co-infection of EBV and HPV is usually found in NPC patients from endemic regions. In one study, NPCs in Iranian patients were detected by in situ hybridization, and a low percentage (15\%) of EBV-positive NPC patients had HPV sequences (HPV type 6/11 or HPV type 16/18) [30]. Approximately 34\% of NPC patients from Morocco had co-infection of HPV and EBV [31]. The co-infection of EBV and HPV was found in $47.7 \%$ of 88 Chinese NPC patients, and the "high-risk" types, including HPV types 16 and 18, accounted for $66.7 \%$ of 45 HPV-positive samples [32]; EBV was associated with types 2 and 3 NPC [the World Health Organization (WHO) classification] [33], which are non-keratinizing-type NPC, indicating that EBV infection might facilitate HPV infection.

However, co-infection of EBV and HPV is less common in NPC patients from some regions in the United States compared with that from the South China. HPV might be the etiologic factor in some EBV-negative, non-keratinizing NPC patients, including Caucasian North American patients [17]. A recent study in a population with a low incidence of NPC reported that both HPV-positive and EBV-positive NPC patients had similar overall survival (OS), whereas the HPV-positive, EBV-negative NPC group had shorter OS [28], which supported the etiologic role of HPV in NPC. Dogan et al. [28] reported that HPV and EBV infections were mutually exclusive in a low NPC incidence population; however, HPV positivity was significantly associated with WHO grade 2 tumors [34]. Numerous clinical studies reported that HPV type
18 infection was detected in NPC tumor tissues (mainly WHO type II) [14, 16, 17, 30, 31, 35, 36]; moreover, HPV types 16, 31, 35, 45, and 48 were detected in Moroccan patients with NPC type III [31]. As a result, HPV infection may act alone and have an etiologic role in the development of non-endemic, EBV-negative NPC, which is consistent with the results of the study of Caucasian North American patients with NPC [27] and another study of a United Kingdom population [37]. Both studies also indicated that EBV-negative NPC were associated with worse outcomes independent of HPV infection compared with EBV-positive NPC. Additionally, EBVnegative NPC in Caucasian patients was associated with smoking and the presence of HPV [38]. In contrast, EBVnegative NPC was not associated with HPV infection in Chinese patients [38, 39].

Using established EBV-negative NPC cell lines and advanced molecular biology techniques, our understanding of molecular alternations in these cells has been tremendously improved [40-43]. Until recently, only a few NPC cell lines, such as C666-1, that stably harbor the EBV genome have been used as EBV-positive models [44]. Other cell lines, such as CNE2, 5-8F, and 6-10B, may be EBV-positive in early cell culture passages, but the EBV genome was lost after subsequent passages. In these cells, it was determined that a single HeLa-related somatic cell hybrid was misidentified as an EBV-negative NPC cell line because the short tandem repeat profiles in NPC cell lines were not completely matched with that in HeLa cells [45]. Moreover, RNA sequencing showed that for HPV type 18-positive cervical adenocarcinoma cells, HeLa cells were a likely source of contamination in NPC cells CNE1 and HONE1 [46]. A new breakpoint and integration pattern has been observed and is being used to differentiate cells. It is also possible that these NPC cell lines derived from patients might have naturally acquired HPV infection prior to the establishment [16]. In contrast, low p53 expression was reportedly in HeLa cells, whereas CNE1 and HNE2 NPC cells had a high level of p53 expression [42, 47, 48]. Interestingly, these cells were not NPC type II, in which HPV type 18 is always detected [31]. HPV integrates into the host genome of HeLa cells [49] and cervical cancer tissues [50]; because EBV and HPV infections are mutually exclusive, it is easy to understand how the EBV genome could be lost during passaging these cells while HPV type 18 could still be detected. Moreover, HPV type 18 infection was not detected in other EBV-positive cells, such as AGS-EBV [51] and Akata-EBV [52], indicating that these cell lines might be used as good cell models for EBV-related research.

Co-infection of EBV and HPV is frequently found in endemic NPC, but it is less common in Caucasians than in Asian populations; HPV is an important etiologic 
factor in EBV-positive NPC among Caucasians [15]. Furthermore, co-infection of HPV and EBV may also cooperatively affect neoplastic transformation [53]. However, although HPV plays an etiologic role in EBV-negative NPC in Caucasians, more evidence is needed to confirm the roles of HPV in EBV-positive NPC in non-endemic regions. Moreover, several questions require further elucidation. First, there is a high risk of co-infection of EBV and HPV in some regions, such as South China, but the ratio of co-infection of EBV and HPV in NPC patients remains unclear. Next, it is also unclear which virus, either EBV or HPV, contributes to the first infection in co-infected patients. It will be interesting to address the difference in pathological and epidemiological characteristics among these NPC patients. Finally, the possible association of the HPV subtype and etiology in NPC requires further investigation. Of note, although genetic susceptibility of NPC in Asian ethnic groups has been well addressed [54-56], the association between genetic susceptibility factors and co-infection of HPV and EBV remains obscure.

\section{Co-existence of EBV and HPV in cervical cancer}

Cervical cancer is the third most common malignancy in women and the fourth most common cause of death from cancer [57]. It is well known that there is a strong association between high-risk HPVs and cervical cancer [58]. Because it takes a long time for patients from being infected by HPV to developing cervical cancer, HPV is found in nearly $100 \%$ of cervical carcinoma cases; however, most women infected do not develop the disease, suggesting that other etiologies may be involved in the carcinogenesis of cervical neoplasm.

Many studies have found that there is a co-infection of high-risk HPV and EBV in cervical tissues [39, 59, 60], whereas some early reports did not report this finding $[61,62]$. It would be of clinical significance to confirm whether EBV plays a causal role in cervical cancer development or if it is merely a bystander in the process.

EBV can transform cells bearing the EBV/C3d (third component of complement, C3) receptor, making them receptive to other oncogenic stimuli [63, 64]. These receptors are widely expressed on ecto- and endo-cervical biopsies of the uterine cervix [65]. This indicates that EBV can be a "helper" in the development of cervical cancer. Unexpectedly, EBV can be sexually transmitted [66] and can replicate in cervical cells [67]. Similarly, chronic cervicitis may also facilitate the EBV infection [68]. Women with cervical intraepithelial neoplasia 1 (CIN1) or greater are almost four times likely to be EBV-positive than women without the disease [68]. EBV prevalence is associated with older age and a diagnosis of CIN1 or greater. In cervical carcinoma, the co-infection rate was the highest (67\%) in squamous cell carcinoma, whereas it was the lowest (7\%) in normal cervical tissue [59]. The remarkable difference in EBV infection noted between normal cervixes and squamous cell carcinoma suggests that the co-infection of the two viruses in the cervix may facilitate cervical cancer progression and act as a marker of poor prognosis in patients with cervical cancer.

HPV types 16 and 18 are the two most common highrisk HPV types and were involved in the development of cervical cancer $[69,70]$. HPV type 58 is relatively prevalent in China and other Asian countries, and genomewide analysis confirmed its expression in cervical lesions [71-74]. The infection of both high-risk HPV types (such as HPV type 58) and EBV display considerable geographic variation, and, prior to performing epidemiologic studies, it is necessary to determine which HPV type might co-infect with EBV. Moreover, the clinical relevance of genital infection caused by EBV may be due to the virus's capability for cellular transformation, which possibly contributes, as a co-factor, to the development of malignancy.

\section{EBV and HPV in breast cancer}

Breast cancer is the second leading cause of cancerrelated death in women around the world [75]. The etiology of human breast cancer is significantly affected by multiple risk factors (age, hormones, alcohol use, diet, familial history, etc.). As viruses are etiologic agents of some human cancers, researchers have become interested in identifying viral agents for breast cancer.

Interest in EBV as a possible breast agent arose from the presence of EBV in breast tissue [76]. Some researchers have also proposed that HPV is a candidate virus in breast cancer after finding that oncogenic HPV could immortalize human mammary epithelial cells [77]. Interestingly, HPV-16 E6/E7, the genotype that is most frequently detected in cervical uterine cancer, was the only genotype identified in HPV-positive breast cancer and integrated into the host genome in all cases. No HPV DNA sequences were found in invasive breast carcinoma [78, 79]. However, high-risk HPV types 16, 18, and 33 have been identified in breast cancers from widely different populations [80]. Clearly, HPV and EBV prevalence in mammary epithelial cells from breast cancer patients is relatively low; therefore, determining the direct etiologic role of these viruses is excluded.

EBV is a major contributor to Hodgkin lymphoma, and significant associations exist between the incidence of Hodgkin lymphoma and breast cancer, suggesting that EBV may act as an etiologic factor for some breast cancers [81]. Some EBV-positive cancer cells have the same histological characteristics as Reed-Sternberg cells, suggesting that EBV-positive lymphocytes infiltrate breast 
tissues and transmit EBV to breast epithelial cells [21]. Women with HPV-positive breast cancer at the age of diagnosis are younger than those with HPV-negative breast cancer [21], supporting the hypothesis that women with HPV-positive breast cancer may have sexually transmitted HPV [82].

Co-infection of EBV and HPV appears to be present in a significantly higher proportion in breast cancers than in normal breast epithelial cells [21, 83]. The Glenn group reported that HPV and EBV co-exist in several human cancers, and the presence of these viruses in breast cancer is associated with young age at diagnosis and, possibly, an increased breast cancer grade [21].

As many studies provide insufficient evidence, testing in larger sample groups is needed to demonstrate that EBV and HPV are associated with breast cancer [84]. To clarify whether the co-infection of EBV and HPV promotes the development of breast cancer, further studies are needed.

\section{EBV and HPV in prostate cancer and other malignancies}

Among men, prostate cancer is the most common cancer and the second leading cause of cancer-related death [85]. Because HPV is always detected in both benign and malignant prostate tissues, it is considered an important risk factor for prostate cancer [86].

Although EBV is a ubiquitous virus with known oncogenic potential, few investigations have demonstrated its association with prostate cancer. Several reports showed that EBV was present in prostate tissues. In Sweden, EBV was present in $8.8 \%$ (31 of 352) of benign and malignant prostate tissues [87], and in the United States, EBV was present in $8 \%$ (16 of 200) of all normal, benign, and malignant prostate tissues [88]. In another study, approximately $37 \%$ (7 of 19) of prostate cancer patients had EBV infection [89].
Both HPV type 18 and EBV gene (EBNA1) sequences were identified in a high and approximately equal proportion of normal, benign, and prostate cancer specimens [20]. The sequences were located in the nuclei of prostate epithelial cells. These observations are consistent with those in studies of high-risk HPVs [86] and studies of EBV in prostate cancer [20,88,89]. The frequency of co-infection of EBV and HPV was significantly higher in prostate cancer (55\%) than in benign (15\%) and normal prostate (30\%) specimens. Additionally, experimental evidence shows that HPV and EBV work together to promote the proliferation of cultured cervical cells [23], suggesting the same may be true for prostate epithelial cells.

We summarized the ratio of co-infection of EBV and HPV in several malignancies (Table 1). It is possible that HPV exerts its oncogenic influences in concert with cofactors, including a possible collaboration with EBV. Although the prostate is a niche for multiple viral and other infections, some of which have oncogenic potential, few investigations have focused on the relationship between prostate cancer and viral infection. Increasing data are needed to clarify the role that the co-infection of HPV and EBV plays in the carcinogenesis of prostate cancer.

Lung cancer is the leading cause of cancer-related death in the world, and it is unlikely that HPV or EBV are important etiologic agents in lung adenocarcinoma, even among people who have never smoked [90]; in fact, in one study, only 1 of 219 patients with lung squamous cell carcinoma tumors was positive for HPV 16 [91]. Gastric carcinoma is the second leading cause of cancer-related death in developed and developing countries, and it has a widely varying geographic incidence [92]. In one study, RNA sequencing demonstrated that only $5.6 \%$ of gastric carcinoma cases harbored EBV-encoded transcripts, and none of the tumors showed evidence of EBV integration into the host genome [91]. Another report indicated that

Table 1 Summary of co-infection of EBV and HPV in several malignancies

\begin{tabular}{lllll}
\hline Tumor type & Co-infection & Subtype of HPV & EBV product(s) & Reference \\
\hline NPC & $15 \%$ (Iran) & $6 / 11,16 / 18$ & EBER & [30] \\
& $34 \%$ (Morocco) & $16,31,45,48$ & EBER & {$[31]$} \\
& $42 \%$ (China) & 18 & EBER & [32] \\
Cervical cancer & $31.8 \%$ & $16,18,58$ & EBER & {$[39]$} \\
& $12.5 \%-69 \%$ & 16,18 & BALF1, BARF-1, LMP1 & EBNA3B \\
Breast cancer & $21.2 \%-64.3 \%$ & 16,18 & LMP1, EBNA-1 & {$[60]$} \\
Prostate cancer & $35 \%$ & $16,18,33$ & EBER & {$[21]$} \\
& $8.8 \%$ (Sweden) & 18 & EBER, EBNA-1 & [88] \\
\hline
\end{tabular}

EBV Epstein-Barr virus; HPV human papillomavirus; NPC nasopharyngeal carcinoma; EBER EBV-encoded RNA; BALF1 BamH1 A fragment leftward reading frame 1; BARF$1 \mathrm{BamH} 1-\mathrm{A}$ right frame 1; $L M P 1$ latent membrane protein 1; EBNA3B EBV nuclear antigen $3 \mathrm{~B} ; \mathrm{EBNA}-1 \mathrm{EBV}$ nuclear antigen 
EBV integration was found in approximately $9 \%$ of malignant epithelial cells in gastric carcinoma [93].

Esophageal squamous cell carcinoma (ESCC) is prevalent worldwide and is particularly common in certain regions in Asia, including Southeast China. One group of researchers showed that EBV infection contributed to the molecular pathogenesis of ESCC [94], whereas other groups indicated that EBV was not associated with ESCC [95, 96]. On the basis of the causal relationship between HPV infection and the carcinogenesis of ESCC, serological evidence from a high-incidence area of China further supports that ESCC is infected with HPV type 16 [9799]; however, this finding contradicted that of another group [100]. Clearly, the prevalence of co-infection of EBV and HPV in ESCC requires further study.

Altogether, it is unclear whether the co-existence of EBV and HPV acts as a promoter or bystander in the development of these carcinomas aforementioned. To improve the treatment and prognosis, it is important, from the standpoint of genetic etiology, to clarify the connection.

\section{APOBEC3 deaminases may promote co-infection of EBV and HPV}

Oncogenic viruses induce cancer by a variety of mechanisms that do not include the viral episome or lytic replication; for example, the immune system can have a deleterious or protective role, with increasing immunosuppression in human virus-associated cancers and with activating DNA damage response [4, 101]. Recently, a family of proteins that includes the apo lipoprotein $B$ mRNA editing enzyme catalytic polypeptide 3 (APOBEC3) was well characterized due to the ability to provide innate immunity from a variety of exogenous pathogens, including viral infection [102, 103]. Cytidine deaminases of the APOBEC3 family all have specificity for single-stranded DNA, which may become exposed during replication or transcription of double-stranded DNA. Three human APOBEC3A (hA3A), hA3B, and $\mathrm{hA} 3 \mathrm{H}$ genes are expressed in keratinocytes and the skin; all of them induce hypermutation in HPV16 DNA upon beta interferon stimulation in benign and precancerous lesions during natural viral infection [104-106]. Interestingly, APOBEC3 is capable of editing both EBV and HPV by inducing cytidine-to-uracil mutations in viral DNA [107]. In one study of early-stage breast carcinogenesis, HPV type 18 infection induced APOBEC3B activity, leading to genome instability [108], whereas in another study APOBEC3 induced E2 hypermutation in HPV16 DNA upon beta interferon stimulation in cervical keratinocytes [105]. In HPV-induced tumorigenesis, APOBEC3 also mutated other host genomic regions, including those of phosphatidylinositol-4,5-bisphosphate 3-kinase, catalytic subunit alpha (PIK3CA) helical domain [109]. Interestingly, EBV-positive gastric cancer displayed recurrent PIK3CA mutations [110]. It is possible that APOBEC3 increases the chance of viral DNA integration in the host by inducing mutations and genome instability after viral infection.

\section{Perspectives and conclusions}

Studies on the roles of chromatin in the regulation of viral infections have revealed the significance of dynamic viral-host chromatin interactions in determining viral infections as well as the interplay between viral-encoded proteins in modulating chromatin. These interactions are especially significant for multiple epigenetic events, such as chromatin assembly, histone and DNA modifications, and higher-order chromosome structures that control viral episome generation and maintenance after viral infection [111-113]. Two scenarios of cooperation between EBV and HPV after co-infection in cancer development should be further addressed; the detailed epigenetic mechanism of this cooperation remains largely unknown, and further studies are necessary to elucidate whether co-infection of EBV and HPV plays any role in the development of malignant tumors. Moreover, chromatin control of viral co-infection also represents a new field with potential targets for the development of novel antiviral therapies. Of note, most arguments of co-infection are mainly supported only by polymerase chain reaction data and in situ hybridization; additional evidence of co-infection of both EBV and HPV or gene products to the same cells or tissues should be addressed.

The effect of such reprogramming on the viral life cycle also remains unknown; it will be interesting to evaluate the host-virus interactions through combined genomewide analyses. Recently, a large-scale functional genomic analysis of EBV, together with over 700 publicly available high-throughput sequencing data sets for human lymphoblastoid cell lines, were mapped to the EBV genome, and viral lytic genes were found co-expressed with cellular cancer-associated pathways, indicating that the lytic cycle may play an unexpected role in virus-mediated oncogenesis [114, 115]. Moreover, a comprehensive resource describing a systematic quantitative analysis of temporal changes in the host and viral proteins throughout the course of a productive infection could provide dynamic views into virus-host interactions [116]. Further studies on genome-wide approaches will lead to more comprehensive models of viral persistence and its role in the interplay between co-infection of EBV and HPV and the infected cells.

Oncogenic virus-induced cancers are an important global concern. Remarkable progress continues to be made in the global fight against cancer by preventing the 
spread of these viruses, by developing and distributing safe and effective vaccines against them, and by identifying the oncogenic mechanisms used by these viruses, enabling the development of new treatment options for these virally associated human malignancies. Although there is a vaccine for HPV [117], there is not one for EBV (50 years after EBV was identified). Now, two preventive vaccines for HPV types $16 / 18$ and HPV types $6 / 11 / 16 / 18$ are commercially available in more than 140 countries and regions, and the implementation rate of these two HPV vaccines has reached approximately $80 \%$ among suitable women in Australia. Interestingly, DZ1 is regarded as a phosphorothioate-modified "10-23," DNAzymes were specifically targeted to the LMP1 mRNA, and DZ1 treatment increases the radiosensitivity of NPC to standard radiotherapy [118-125]. The DZ1 treatment is safe and has been shown to be efficacious in different modes, indicating the potential for DZ1 therapeutic approaches for the treatment of EBV-related cancers.

\section{Authors' contributions}

YS and YT drafted the manuscript. YS, LY, XC, YT, and YC participated in the design of the study. SP, XC, and YC participated in its design and coordination and helped to draft the manuscript. All authors read and approved the final manuscript.

\section{Author details \\ ${ }^{1}$ Cancer Research Institute, Central South University, Changsha 410078, Hunan, P. R. China. ${ }^{2}$ Key Laboratory of Carcinogenesis and Cancer Invasion, Ministry of Education, Changsha 410078, Hunan, P. R. China. ${ }^{3}$ Key Laboratory of Carcinogenesis, National Health and Family Planning Commission, Chang- sha 410078, Hunan, P. R. China.}

\section{Acknowledgements}

We would like to thank all of the laboratory members for their critical discussion of this manuscript, and we apologize for all of the excellent papers not mentioned due to space limitations.

This work was supported by the National Basic Research Program of China [2011CB504300 (Y.T.; Y.C.), 2015 CB553903 (Y.T.)]; the National High Technology Research and Development Program of China (863 Program) [2012AA02A501 (Y.C.)]; the National Natural Science Foundation of China $[81,171,881$ and 81372427 (Y.T.), 81271763 (S.L.), 81,302,354 (Y.S.)]; and the Hunan Natural Science Foundation of China [12JJ1013 (Y.T.)].

\section{Competing interests}

The authors declare that they have no conflicts of interest.

Received: 22 March 2015 Accepted: 7 August 2015

Published online: 22 January 2016

\section{References}

1. Schiller JT, Lowy DR. Virus infection and human cancer: an overview. Recent Results Cancer Res. 2014;193:1-10.

2. Zur Hausen $\mathrm{H}$. The search for infectious causes of human cancers: where and why. Virology. 2009;392(1):1-10.

3. de Martel C, Ferlay J, Franceschi S, Vignat J, Bray F, Forman D, et al. Global burden of cancers attributable to infections in 2008: a review and synthetic analysis. Lancet Oncol. 2012;13(6):607-15.

4. Mesri EA, Feitelson MA, Munger K. Human viral oncogenesis: a cancer hallmarks analysis. Cell Host Microbe. 2014;15(3):266-82.

5. Kutok JL, Wang F. Spectrum of Epstein-Barr virus-associated diseases. Annu Rev Pathol. 2006;1:375-404.
6. Dolcetti R, Dal Col J, Martorelli D, Carbone A, Klein E. Interplay among viral antigens, cellular pathways and tumor microenvironment in the pathogenesis of EBV-driven lymphomas. Semin Cancer Biol. 2013;23(6):441-56.

7. Brooks L, Yao QY, Rickinson AB, Young LS. Epstein-Barr virus latent gene transcription in nasopharyngeal carcinoma cells: coexpression of EBNA1, LMP1, and LMP2 transcripts. J Virol. 1992;66(5):2689-97.

8. Plottel CS, Blaser MJ. Microbiome and malignancy. Cell Host Microbe. 2011;10(4):324-35.

9. Lieberman PM. Virology. Epstein-Barr virus turns 50. Science. 2014;343(6177):1323-5

10. McLaughlin-Drubin ME, Meyers J, Munger K. Cancer associated human papillomaviruses. Curr Opin Virol. 2012;2(4):459-66.

11. Trivedi P, Takazawa K, Zompetta C, Cuomo L, Anastasiadou E, Carbone A, et al. Infection of HHV-8 + primary effusion lymphoma cells with a recombinant Epstein-Barr virus leads to restricted EBV latency, altered phenotype, and increased tumorigenicity without affecting TCL1 expression. Blood. 2004;103(1):313-6.

12. de Elgui Oliveira D. DNA viruses in human cancer: an integrated overview on fundamental mechanisms of viral carcinogenesis. Cancer Lett. 2007;247(2):182-96.

13. Rickinson AB. Co-infections, inflammation and oncogenesis: future directions for EBV research. Semin Cancer Biol. 2014;26C:99-115.

14. Giannoudis A, Ergazaki M, Segas J, Giotakis J, Adamopoulos G, Gorgoulis $V$, et al. Detection of Epstein-Barr virus and human papillomavirus in nasopharyngeal carcinoma by the polymerase chain reaction technique. Cancer Lett. 1995;89(2):177-81.

15. Punwaney R, Brandwein MS, Zhang DY, Urken ML, Cheng R, Park CS, et al. Human papillomavirus may be common within nasopharyngeal carcinoma of Caucasian Americans: investigation of Epstein-Barr virus and human papillomavirus in eastern and western nasopharyngeal carcinoma using ligation-dependent polymerase chain reaction. Head Neck. 1999;21(1):21-9.

16. Singhi AD, Califano J, Westra WH. High-risk human papillomavirus in nasopharyngeal carcinoma. Head Neck. 2012;34(2):213-8.

17. Rassekh CH, Rady PL, Arany I, Tyring SK, Knudsen S, Calhoun KH, et al. Combined Epstein-Barr virus and human papillomavirus infection in nasopharyngeal carcinoma. Laryngoscope. 1998;108(3):362-7.

18. Prayitno A. Cervical cancer with human papilloma virus and Epstein Barr virus positive. J Carcinog. 2006;5:13.

19. Sasagawa T, Shimakage M, Nakamura M, Sakaike J, Ishikawa H, Inoue M. Epstein-Barr virus (EBV) genes expression in cervical intraepithelial neoplasia and invasive cervical cancer: a comparative study with human papillomavirus (HPV) infection. Hum Pathol. 2000;31(3):318-26.

20. Whitaker NJ, Glenn WK, Sahrudin A, Orde MM, Delprado W, Lawson JS. Human papillomavirus and Epstein Barr virus in prostate cancer: koilocytes indicate potential oncogenic influences of human papillomavirus in prostate cancer. Prostate. 2013;73(3):236-41.

21. Glenn WK, Heng B, Delprado W, lacopetta B, Whitaker NJ, Lawson JS. Epstein-Barr virus, human papillomavirus and mouse mammary tumour virus as multiple viruses in breast cancer. PLoS One. 2012;7(11):e48788.

22. Al Moustafa AE, Chen D, Ghabreau L, Akil N. Association between human papillomavirus and Epstein-Barr virus infections in human oral carcinogenesis. Med Hypotheses. 2009;73(2):184-6.

23. Ammatuna P, Giovannelli L, Giambelluca D, Mancuso S, Rubino E, Colletti $P$, et al. Presence of human papillomavirus and Epstein-Barr virus in the cervix of women infected with the human immunodeficiency virus. J Med Virol. 2000;62(4):410-5.

24. Wei KR, Zheng RS, Zhang SW, Liang ZH, Ou ZX, Chen WQ. Nasopharyngeal carcinoma incidence and mortality in China in 2010. Chin J Cancer. 2014;33(8):381-7.

25. Xu ZJ, Zheng RS, Zhang SW, Zou XN, Chen WQ. Nasopharyngeal carcinoma incidence and mortality in China in 2009. Chin J Cancer. 2013;32(8):453-60.

26. Young LS, Dawson CW. Epstein-Barr virus and nasopharyngeal carcinoma. Chin J Cancer. 2014;33(12):581-90

27. Maxwell JH, Kumar B, Feng FY, McHugh JB, Cordell KG, Eisbruch A, et al. HPV-positive/p16-positive/EBV-negative nasopharyngeal carcinoma in white North Americans. Head Neck. 2010;32(5):562-7. 
28. Dogan S, Hedberg ML, Ferris RL, Rath TJ, Assaad AM, Chiosea SI. Human papillomavirus and Epstein-Barr virus in nasopharyngeal carcinoma in a low-incidence population. Head Neck. 2014;36(4):511-6.

29. Tyan YS, Liu ST, Ong WR, Chen ML, Shu CH, Chang YS. Detection of Epstein-Barr virus and human papillomavirus in head and neck tumors. J Clin Microbiol. 1993;31(1):53-6.

30. Mirzamani N, Salehian P, Farhadi M, Tehran EA. Detection of EBV and HPV in nasopharyngeal carcinoma by in situ hybridization. Exp Mol Pathol. 2006:81(3):231-4

31. Laantri N, Attaleb M, Kandil M, Naji F, Mouttaki T, Dardari R, et al. Human papillomavirus detection in moroccan patients with nasopharyngeal carcinoma. Infect Agent Cancer. 2011;6(1):3.

32. Tung YC, Lin KH, Chu PY, Hsu CC, Kuo WR. Detection of human papilloma virus and Epstein-Barr virus DNA in nasopharyngeal carcinoma by polymerase chain reaction. Kaohsiung J Med Sci. 1999;15(5):256-62.

33. Brennan B. Nasopharyngeal carcinoma. Orphanet J Rare Dis. 2006;1:23.

34. Stenmark MH, MCHugh JB, Schipper M, Walline HM, Komarck C, Feng FY, et al. Nonendemic HPV-positive nasopharyngeal carcinoma: association with poor prognosis. Int J Radiat Oncol Biol Phys. 2014;88(3):580-8.

35. Hording U, Nielsen HW, Daugaard S, Albeck H. Human papillomavirus types 11 and 16 detected in nasopharyngeal carcinomas by the polymerase chain reaction. Laryngoscope. 1994;104(1 Pt 1):99-102.

36. Lo EJ, Bell D, Woo JS, Li G, Hanna EY, El-Naggar AK, et al. Human papillomavirus and WHO type I nasopharyngeal carcinoma. Laryngoscope. 2010;120(10):1990-7.

37. Robinson M, Suh YE, Paleri V, Devlin D, Ayaz B, Pertl L, et al. Oncogenic human papillomavirus-associated nasopharyngeal carcinoma: an observational study of correlation with ethnicity, histological subtype and outcome in a UK population. Infect Agent Cancer. 2013;8(1):30.

38. Lin Z, Khong B, Kwok S, Cao H, West RB, Le QT, et al. Human papillomavirus 16 detected in nasopharyngeal carcinomas in white Americans but not in endemic Southern Chinese patients. Head Neck. 2014;36(5):709-14.

39. Szkaradkiewicz A, Wal M, Kuch A, Pieta P. Human papillomavirus (HPV) and Epstein-Barr virus (EBV) cervical infections in women with normal and abnormal cytology. Pol J Microbiol. 2004;53(2):95-9.

40. Song X, Tao YG, Zeng L, Deng XY, Lee LM, Gong JP, et al. Latent membrane protein 1 encoded by Epstein-Barr virus modulates directly and synchronously cyclin D1 and p16 by newly forming a c-Jun/ Jun B heterodimer in nasopharyngeal carcinoma cell line. Virus Res. 2005;113(2):89-99.

41. Tao Y, Song X, Deng X, Xie D, Lee LM, Liu Y, et al. Nuclear accumulation of epidermal growth factor receptor and acceleration of G1/S stage by Epstein-Barr-encoded oncoprotein latent membrane protein 1. Exp Cell Res. 2005;303(2):240-51.

42. Li L, Guo L, Tao Y, Zhou S, Wang Z, Luo W, et al. Latent membrane protein 1 of Epstein-Barr virus regulates p53 phosphorylation through MAP kinases. Cancer Lett. 2007;255(2):219-31.

43. Jin X, Song X, Li L, Wang Z, Tao Y, Deng L, et al. Blockade of AP-1 activity by dominant-negative TAM67 can abrogate the oncogenic phenotype in latent membrane protein 1-positive human nasopharyngeal carcinoma. Mol Carcinog. 2007:46(11):901-11.

44. Cheung ST, Huang DP, Hui AB, Lo KW, Ko CW, Tsang YS, et al. Nasopharyngeal carcinoma cell line (C666-1) consistently harbouring Epstein-Barr virus. Int J Cancer. 1999:83(1):121-6.

45. Chan SY, Choy KW, Tsao SW, Tao Q, Tang T, Chung GT, et al. Authentication of nasopharyngeal carcinoma tumor lines. Int J Cancer. 2008;122(9):2169-71.

46. Strong MJ, Baddoo M, Nanbo A, Xu M, Puetter A, Lin Z. Comprehensive high-throughput RNA sequencing analysis reveals contamination of multiple nasopharyngeal carcinoma cell lines with HeLa cell genomes. J Virol. 2014;88(18):10696-704.

47. Li L, Li W, Xiao L, Xu J, Chen X, Tang M, et al. Viral oncoprotein LMP1 disrupts p53-induced cell cycle arrest and apoptosis through modulating K63-linked ubiquitination of p53. Cell Cycle. 2012;11(12):2327-36.

48. Li L, Zhou S, Chen X, Guo L, Li Z, Hu D, et al. The activation of p53 mediated by Epstein-Barr virus latent membrane protein 1 in SV40 large T-antigen transformed cells. FEBS Lett. 2008;582(5):755-62.

49. Adey A, Burton JN, Kitzman JO, Hiatt JB, Lewis AP, Martin BK, et al. The haplotype-resolved genome and epigenome of the aneuploid HeLa cancer cell line. Nature. 2013;500(7461):207-11.
50. Shi Y, Li L, Hu Z, Li S, Wang S, Liu J, et al. A genome-wide association study identifies two new cervical cancer susceptibility loci at $4 \mathrm{q} 12$ and 17q12. Nat Genet. 2013;45(8):918-22

51. Jung YJ, Choi H, Kim H, Lee SK. MicroRNA miR-BART20-5p stabilizes Epstein-Barr virus latency by directly targeting BZLF1 and BRLF1. J Virol. 2014;88(16):9027-37.

52. Takada K, Horinouchi K, Ono Y, Aya T, Osato T, Takahashi M, et al. An Epstein-Barr virus-producer line Akata: establishment of the cell line and analysis of viral DNA. Virus Genes. 1991;5(2):147-56.

53. Chan YH, Lo CM, Lau HY, Lam TH. Vertically transmitted nasopharyngeal infection of the human papillomavirus: does it play an aetiological role in nasopharyngeal cancer? Oral Oncol. 2014;50(5):326-9.

54. Lung ML, Cheung AK, Ko JM, Lung HL, Cheng Y, Dai W. The interplay of host genetic factors and Epstein-Barr virus in the development of nasopharyngeal carcinoma. Chin J Cancer. 2014;33(11):556-68.

55. Young LS. Epstein-Barr virus at 50-future perspectives. Chin J Cancer. 2014;33(11):527-8.

56. Bei JX, Li Y, Jia WH, Feng BJ, Zhou G, Chen LZ, et al. A genome-wide association study of nasopharyngeal carcinoma identifies three new susceptibility loci. Nat Genet. 2010;42(7):599-603.

57. Yang BH, Bray FI, Parkin DM, Sellors JW, Zhang ZF. Cervical cancer as a priority for prevention in different world regions: an evaluation using years of life lost. Int J Cancer. 2004;109(3):418-24.

58. Arbyn M, Snijders PJ, Meijer CJ, Berkhof J, Cuschieri K, Kocjan BJ, et al. Which high-risk HPV assays fulfil criteria for use in primary cervical cancer screening? Clin Microbiol Infect. 2015;21(9):817-26.

59. Khenchouche A, Sadouki N, Boudriche A, Houali K, Graba A, Ooka T, et al. Human papillomavirus and Epstein-Barr virus co-infection in cervical carcinoma in Algerian women. Virol J. 2013;10:340.

60. Santos NB, Villanova FE, Andrade PM, Ribalta J, Focchi J, Otsuka AY, et al. Epstein-Barr virus detection in invasive and pre-invasive lesions of the uterine cervix. Oncol Rep. 2009;21(2):403-5.

61. Yang YY, Koh LW, Tsai JH, Tsai CH, Wong EF, Lin SJ, et al. Correlation of viral factors with cervical cancer in Taiwan. J Microbiol Immunol Infect. 2004;37(5):282-7.

62. de Elgui Oliveira D, Furtado Monteiro TA, de Alencar Melo W, Amaral Reboucas Moreira M, Alvarenga M, Bacchi CE. Lack of EpsteinBarr virus infection in cervical carcinomas. Arch Pathol Lab Med. 1999;123(11):1098-100.

63. Young LS, Dawson CW, Brown KW, Rickinson AB. Identification of a human epithelial cell surface protein sharing an epitope with the C3d/ Epstein-Barr virus receptor molecule of B lymphocytes. Int J Cancer. 1989;43(5):786-94.

64. Sinha SK, Todd SC, Hedrick JA, Speiser CL, Lambris JD, Tsoukas CD Characterization of the EBV/C3d receptor on the human Jurkat T cell line: evidence for a novel transcript. J Immunol. 1993;150(12):5311-20.

65. Se Thoe SY, Wong KK, Pathmanathan R, Sam CK, Cheng HM, Prasad U. Elevated secretory lgA antibodies to Epstein-Barr virus (EBV) and presence of EBV DNA and EBV receptors in patients with cervical carcinoma. Gynecol Oncol. 1993;50(2):168-72.

66. Naher H, Gissmann L, Freese UK, Petzoldt D, Helfrich S. Subclinical Epstein-Barr virus infection of both the male and female genital tractindication for sexual transmission. J Invest Dermatol. 1992;98(5):791-3.

67. Sixbey JW, Lemon SM, Pagano JS. A second site for Epstein-Barr virus shedding: the uterine cervix. Lancet. 1986;2(8516):1122-4.

68. Silver MI, Paul P, Sowjanya P, Ramakrishna G, Vedantham H, Kalpana $B$, et al. Shedding of Epstein-Barr virus and cytomegalovirus from the genital tract of women in a periurban community in Andhra Pradesh. India. J Clin Microbiol. 2011;49(7):2435-9.

69. Yang HJ. Aberrant DNA methylation in cervical carcinogenesis. Chin J Cancer. 2013;32(1):42-8.

70. Tommasino M. The human papillomavirus family and its role in carcinogenesis. Semin Cancer Biol. 2014;26:13-21.

71. Munoz N, Bosch FX, de Sanjose S, Herrero R, Castellsague X, Shah KV et al. Epidemiologic classification of human papillomavirus types associated with cervical cancer. N Engl J Med. 2003;348(6):518-27.

72. Chan PK, Zhang C, Park JS, Smith-McCune KK, Palefsky JM, Giovannelli $\mathrm{L}$, et al. Geographical distribution and oncogenic risk association of human papillomavirus type $58 \mathrm{E} 6$ and E7 sequence variations. Int J Cancer. 2013;132(11):2528-36. 
73. Chan PK. Human papillomavirus type 58: the unique role in cervical cancers in East Asia. Cell Biosci. 2012;2(1):17.

74. Li Y, Wang X, Ni T, Wang F, Lu W, Zhu J, et al. Human papillomavirus type 58 genome variations and RNA expression in cervical lesions. J Virol. 2013;87(16):9313-22.

75. Holm M, Tjonneland A, Balslev E, Kroman N. Prognosis of synchronous bilateral breast cancer: a review and meta-analysis of observational studies. Breast Cancer Res Treat. 2014;146(3):461-75.

76. Labrecque LG, Barnes DM, Fentiman IS, Griffin BE. Epstein-Barr virus in epithelial cell tumors: a breast cancer study. Cancer Res. 1995;55(1):39-45

77. Band V, Zajchowski D, Kulesa V, Sager R. Human papilloma virus DNAs immortalize normal human mammary epithelial cells and reduce their growth factor requirements. Proc Natl Acad Sci U S A. 1990;87(1):463-7.

78. de Cremoux P, Thioux M, Lebigot I, Sigal-Zafrani B, Salmon R, SastreGarau X, et al. No evidence of human papillomavirus DNA sequences in invasive breast carcinoma. Breast Cancer Res Treat. 2008;109(1):55-8.

79. Aguayo F, Khan N, Koriyama C, Gonzalez C, Ampuero S, Padilla O, et al. Human papillomavirus and Epstein-Barr virus infections in breast cancer from chile. Infect Agent Cancer. 2011;6(1):7.

80. Amarante MK, Watanabe MA. The possible involvement of virus in breast cancer. J Cancer Res Clin Oncol. 2009;135(3):329-37.

81. Yasui Y, Potter JD, Stanford JL, Rossing MA, Winget MD, Bronner M, et al. Breast cancer risk and "delayed" primary Epstein-Barr virus infection. Cancer Epidemiol Biomarkers Prev. 2001;10(1):9-16.

82. Akil N, Kassab A, Yasmeen A, Darnel AD, Bismar TA. Al Moustafa AE. Human breast cancer and sexual activities. Br J Cancer. 2008;98(2):508-9 (author reply 510-11).

83. Fina F, Romain S, Ouafik L, Palmari J, Ben Ayed F, Benharkat S, et al. Frequency and genome load of Epstein-Barr virus in 509 breast cancers from different geographical areas. Br J Cancer. 2001;84(6):783-90.

84. Joshi D, Buehring GC. Are viruses associated with human breast cancer? Scrutinizing the molecular evidence. Breast Cancer Res Treat. 2012;135(1):1-15.

85. Martel CL, Gumerlock PH, Meyers FJ, Lara PN. Current strategies in the management of hormone refractory prostate cancer. Cancer Treat Rev. 2003;29(3):171-87.

86. Lin Y, Mao Q, Zheng X, Yang K, Chen H, Zhou C, et al. Human papillomavirus 16 or 18 infection and prostate cancer risk: a meta-analysis. Ir J Med Sci. 2011;180(2):497-503.

87. Bergh J, Marklund I, Gustavsson C, Wiklund F, Gronberg H, Allard A, et al. No link between viral findings in the prostate and subsequent cancer development. Br J Cancer. 2007;96(1):137-9.

88. Sfanos KS, Sauvageot J, Fedor HL, Dick JD, De Marzo AM, Isaacs WB. A molecular analysis of prokaryotic and viral DNA sequences in prostate tissue from patients with prostate cancer indicates the presence of multiple and diverse microorganisms. Prostate. 2008;68(3):306-20.

89. Grinstein S, Preciado MV, Gattuso P, Chabay PA, Warren WH, De Matteo $E$, et al. Demonstration of Epstein-Barr virus in carcinomas of various sites. Cancer Res. 2002;62(17):4876-8.

90. Lim WT, Chuah KL, Leong SS, Tan EH, Toh CK. Assessment of human papillomavirus and Epstein-Barr virus in lung adenocarcinoma. Oncol Rep. 2009;21(4):971-5.

91. Khoury JD, Tannir NM, Williams MD, Chen Y, Yao H, Zhang J, et al. Landscape of DNA virus associations across human malignant cancers: analysis of 3775 cases using RNA-Seq. J Virol. 2013;87(16):8916-26.

92. Cidon EU, Ellis SG, Inam Y, Adeleke S, Zarif S, Geldart T. Molecular targeted agents for gastric cancer: a step forward towards personalized therapy. Cancers (Basel). 2013;5(1):64-91.

93. Murphy G, Pfeiffer R, Camargo MC, Rabkin CS. Meta-analysis shows that prevalence of Epstein-Barr virus-positive gastric cancer differs based on sex and anatomic location. Gastroenterology. 2009;137(3):824-33.

94. Jenkins TD, Nakagawa H, Rustgi AK. The association of Epstein-Barr virus DNA with esophageal squamous cell carcinoma. Oncogene. 1996;13(8):1809-13.

95. Wang J, Noffsinger A, Stemmermann G, Fenoglio-Preiser C. Esophageal squamous cell carcinomas arising in patients from a high-risk area of North China lack an association with Epstein-Barr virus. Cancer Epidemiol Biomarkers Prev. 1999;8(12):1111-4.
96. Sunpaweravong S, Mitarnun W, Puttawibul P. Absence of EpsteinBarr virus in esophageal squamous cell carcinoma. Dis Esophagus. 2005;18(6):398-9.

97. Guo F, Liu Y, Wang X, He Z, Weiss NS, Madeleine MM, et al. Human papillomavirus infection and esophageal squamous cell carcinoma: a casecontrol study. Cancer Epidemiol Biomarkers Prev. 2012;21(5):780-5.

98. Liu F, Guo F, Zhou Y, He Z, Tian X, Guo C, et al. The Anyang Esophageal Cancer Cohort Study: study design, implementation of fieldwork, and use of computer-aided survey system. PLoS One. 2012;7(2):e31602.

99. He Z, Xu Z, Hang D, Guo F, Abliz A, Weiss NS, et al. Anti-HPV-E7 seropositivity and risk of esophageal squamous cell carcinoma in a high-risk population in China. Carcinogenesis. 2014;35(4):816-21.

100. Koshiol J, Wei WQ, Kreimer AR, Chen W, Gravitt P, Ren JS, et al. No role for human papillomavirus in esophageal squamous cell carcinoma in China. Int J Cancer. 2010;127(1):93-100.

101. Nikitin PA, Yan CM, Forte E, Bocedi A, Tourigny JP, White RE, et al. An ATM/Chk2-mediated DNA damage-responsive signaling pathway suppresses Epstein-Barr virus transformation of primary human B cells. Cell Host Microbe. 2010;8(6):510-22.

102. Cullen BR. Role and mechanism of action of the APOBEC3 family of antiretroviral resistance factors. J Virol. 2006;80(3):1067-76.

103. Harris RS, Dudley JP. APOBECs and virus restriction. Virology. 2015;479-480:131-45

104. Vartanian JP, Guetard D, Henry M, Wain-Hobson S. Evidence for editing of human papillomavirus DNA by APOBEC3 in benign and precancerous lesions. Science. 2008;320(5873):230-3.

105. Wang Z, Wakae K, Kitamura K, Aoyama S, Liu G, Koura M, et al. APOBEC3 deaminases induce hypermutation in human papillomavirus 16 DNA upon beta interferon stimulation. J Virol. 2014;88(2):1308-17.

106. Kukimoto I, Mori S, Aoyama S, Wakae K, Muramatsu M, Kondo K. Hypermutation in the E2 gene of human papillomavirus type 16 in cervical intraepithelial neoplasia. J Med Virol. 2015;87(10):1754-60.

107. Suspene R, Aynaud MM, Koch S, Pasdeloup D, Labetoulle M, Gaertner B, et al. Genetic editing of herpes simplex virus 1 and Epstein-Barr herpesvirus genomes by human APOBEC3 cytidine deaminases in culture and in vivo. J Virol. 2011;85(15):7594-602.

108. Ohba K, Ichiyama K, Yajima M, Gemma N, Nikaido M, Wu Q, et al. In vivo and in vitro studies suggest a possible involvement of HPV infection in the early stage of breast carcinogenesis via APOBEC3B induction. PLOS One. 2014;9(5):e97787.

109. Henderson S, Chakravarthy A, Su X, Boshoff C, Fenton TR. APOBECmediated cytosine deamination links PIK3CA helical domain mutations to human papillomavirus-driven tumor development. Cell Rep. 2014;7(6):1833-41.

110. The Cancer Genome Atlas Research Network. Comprehensive molecular characterization of gastric adenocarcinoma. Nature. 2014;513(7517):202-9.

111. Woellmer A, Hammerschmidt W. Epstein-Barr virus and host cell methylation: regulation of latency, replication and virus reactivation. Curr Opin Virol. 2013;3(3):260-5.

112. Lieberman PM. Keeping it quiet: chromatin control of gammaherpesvirus latency. Nat Rev Microbiol. 2013;11(12):863-75.

113. Knipe DM, Lieberman PM, Jung JU, McBride AA, Morris KV, Ott $M$, et al. Snapshots: chromatin control of viral infection. Virology. 2013:435(1):141-56.

114. Arvey A, Tempera I, Tsai K, Chen HS, Tikhmyanova N, Klichinsky M, et al. An atlas of the Epstein-Barr virus transcriptome and epigenome reveals host-virus regulatory interactions. Cell Host Microbe. 2012;12(2):233-45.

115. Arvey A, Tempera I, Lieberman PM. Interpreting the Epstein-Barr Virus (EBV) epigenome using high-throughput data. Viruses. 2013;5(4):1042-54.

116. Weekes MP, Tomasec P, Huttlin EL, Fielding CA, Nusinow D, Stanton RJ, et al. Quantitative temporal viromics: an approach to investigate hostpathogen interaction. Cell. 2014;157(6):1460-72.

117. Schiller JT, Davies P. Delivering on the promise: hPV vaccines and cervical cancer. Nat Rev Microbiol. 2004;2(4):343-7.

118. Lu ZX, Ye M, Yan GR, Li Q, Tang M, Lee LM, et al. Effect of EBV LMP1 targeted DNAzymes on cell proliferation and apoptosis. Cancer Gene Ther. 2005;12(7):647-54. 
119. Lu ZX, Ma XQ, Yang LF, Wang ZL, Zeng L, Li ZJ, et al. DNAzymes targeted to EBV-encoded latent membrane protein-1 induce apoptosis and enhance radiosensitivity in nasopharyngeal carcinoma. Cancer Lett. 2008;265(2):226-38

120. Yang L, Xiao L, Ma X, Tang M, Weng X, Chen X, et al. Effect of DNAzymes targeting Akt1 on cell proliferation and apoptosis in nasopharyngeal carcinoma. Cancer Biol Ther. 2009:8(4):366-71.

121. Ma X, Yang L, Xiao L, Tang M, Liu L, Li Z, et al. Down-regulation of EBVLMP1 radio-sensitizes nasal pharyngeal carcinoma cells via NF-kappaB regulated ATM expression. PLoS One. 2011;6(11):e24647.

122. Ma X, Xu Z, Yang L, Xiao L, Tang M, Lu J, et al. EBV-LMP1-targeted DNAzyme induces DNA damage and causes cell cycle arrest in LMP1-positive nasopharyngeal carcinoma cells. Int J Oncol. 2013;43(5):1541-8.
123. Chen Y, Yang L, Huang S, Li Z, Zhang L, He J, et al. Delivery system for DNAzymes using arginine-modified hydroxyapatite nanoparticles for therapeutic application in a nasopharyngeal carcinoma model. Int J Nanomedicine. 2013:8:3107-18.

124. Yang $L, X u Z$, Liu L, Luo X, Lu J, Sun L, et al. Targeting EBV-LMP1 DNAzyme enhances radiosensitivity of nasopharyngeal carcinoma cells by inhibiting telomerase activity. Cancer Biol Ther. 2014;15(1):61-8.

125. Cao Y, Yang L, Jiang W, Wang X, Liao W, Tan G, et al. Therapeutic evaluation of Epstein-Barr virus-encoded latent membrane protein-1 targeted DNAzyme for treating of nasopharyngeal carcinomas. Mol Ther. 2014;22(2):371-7.

\section{Submit your next manuscript to BioMed Central and we will help you at every step:}

- We accept pre-submission inquiries

- Our selector tool helps you to find the most relevant journal

- We provide round the clock customer support

- Convenient online submission

- Thorough peer review

- Inclusion in PubMed and all major indexing services

- Maximum visibility for your research

Submit your manuscript at www.biomedcentral.com/submit
() Biomed Central 